\title{
Design and cold model experiment of a continuous-wave deuteron radio-frequency quadrupole
}

\author{
Q. Fu, K. Zhu, ${ }^{*}$ Y. R. Lu, ${ }^{\dagger}$ M. J. Easton, S. L. Gao, Z. Wang, F. J. Jia, H. P. Li, and P. P. Gan \\ State Key Laboratory of Nuclear Physics and Technology, Peking University, \\ Beijing 100871, China \\ Y. $\mathrm{He}$ \\ Institute of Modern Physics, China Academy of Science, Lanzhou 730000, China
}

(Received 17 January 2017; published 22 December 2017)

\begin{abstract}
A deuteron radio-frequency quadrupole ( $\mathrm{RFQ}$ ) is being built by the RFQ group at Peking University. It is a very compact high-current RFQ, operating at $162.5 \mathrm{MHz}$ in continuous-wave mode. By optimizing the beam dynamics design, our simulations reached $98 \%$ transmission efficiency for acceleration of the 50-mA deuteron beam from $50 \mathrm{keV}$ to $1 \mathrm{MeV}$, with an intervane voltage of $60 \mathrm{kV}$ and a length of $1.809 \mathrm{~m}$. This RFQ adopts a window-type structure, with low power consumption and sufficient mode separation, with no stabilizing rods required. Its magnetic coupling windows have been optimized by both electromagnetic simulation and the construction of an equivalent circuit model. The empirical equation based on the circuit model provides a new way to evaluate the effect of the window size on the frequency. In addition, an aluminum model of the full-length RFQ has been built and tested, and the results show good agreement with the simulations. During the tuning process, the magnetic coupling effect between quadrants was found to be unique to the window-type RFQ. We also propose a method to estimate the effects of different degrees of electric field unflatness on the beam transmission. For the cooling system design, the results of thermostructural analysis, verified by comparing results from ANSYS and CST, show that the special cooling channels provide a high cooling efficiency around the magnetic coupling windows. The maximal deformation of the structure was approximately $75 \mu \mathrm{m}$. The beam-loading effect caused by a high current, and the coupler design, are also discussed.
\end{abstract}

DOI: 10.1103/PhysRevAccelBeams.20.120101

\section{INTRODUCTION}

Since it was invented in 1970 [1], the radio-frequency quadrupole (RFQ) accelerator has been widely used as an injector in linear accelerator systems, a compact neutron source for radiography and material detection, an ion implanter for material improvement, an isotope production unit in medical fields, and an accelerator-based diagnostic in magnetic fusion devices [2]. Especially in recent decades, to meet these application requirements, more and more RFQs have been designed and built for high-current continuous beams: first the LEDA RFQ [3] and then others such as the TRASCO RFQ [4], IPHI RFQ [5], SARAF RFQ [6], and the IFMIF RFQ [7]. However, for high-current continuous-wave (cw) RFQs, the space charge effect, beam-loading effect, and

\footnotetext{
Corresponding author. zhukun@pku.edu.cn

Corresponding author. yrlu@pku.edu.cn
}

Published by the American Physical Society under the terms of the Creative Commons Attribution 4.0 International license. Further distribution of this work must maintain attribution to the author(s) and the published article's title, journal citation, and DOI. power losses all become serious, easily causing beam losses, operation instability, or even components burning down. So until now, few RFQs have been confirmed to operate stably for a long time in the $\mathrm{cw}$ mode and even fewer for deuteron beams. Our $50-\mathrm{mA} \mathrm{cw}$ deuteron RFQ is designed to challenge the difficulties in beam dynamics design, rf structure design, cooling, and power coupling system. Moreover, if this short $1.8-\mathrm{m}$ RFQ were connected to a short 1.3-m drift tube linac (DTL), a beam of $4-\mathrm{MeV}$ deuterons could be obtained in a much shorter length than an equivalent single RFQ, which would be roughly $8 \mathrm{~m}$ long. This combination also consumes less than $90 \mathrm{~kW}$ of rf power because of the high accelerating gradient of the DTL [8]. Thus, it would be a very efficient injector for compact neutron sources.

As shown in Fig. 1, our RFQ design adopts a four-vane structure with magnetic coupling windows, which was first proposed by Institution of Theoretical and Experimental Physics of Russia in 1993 [9], now often called a windowtype RFQ. Compared to a normal four-vane RFQ, a windowtype RFQ is more compact and needs no $\pi$-mode stabilizing rods or dipole rods, thereby reducing the structural complexity. It also has a more stable structure and lower power demands than a four-rod RFQ and, therefore, is more suitable for the cw mode. Several window-type RFQs have been 


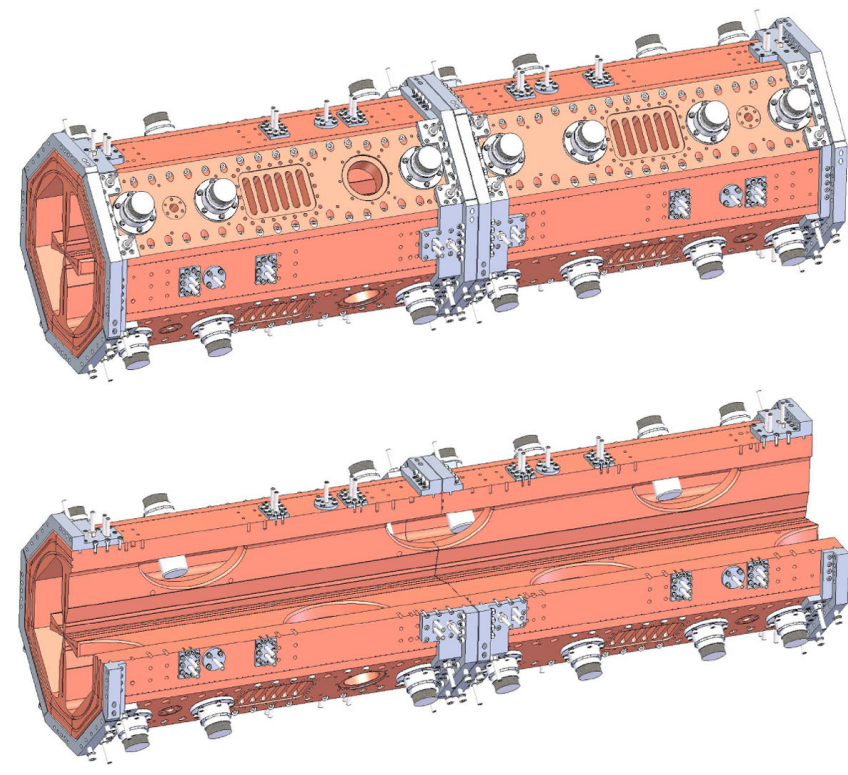

FIG. 1. Detailed 3D engineering model of the copper RFQ cavity made in two segments. The adjustable aluminum tuners will be replaced with fixed copper tuners after low-power tuning.

through power or beam commissioning, such as the Terawatt Accumulator RFQ [10], Argonne Tandem Linac Accelerator System RFQ [11,12], and the RFQ for Nuclotron-based Ion Collider Facility [13]. Although they operate at a low frequency, they provide our RFQ with valuable references for design, fabrication, and testing.

To ensure the stable operation of our RFQ, we have built two aluminum cold models to validate the reliability of the simulations. The second model has the same length, vane modulations, and machining processes as the future copper cavity but was not brazed or put under a vacuum. Based on the measured field in the cold model, we carried out a tolerance analysis to estimate the influence of the electric field unflatness on the beam transmission.

In this paper, Secs. II and III describe the detailed beam dynamics and rf structure design, respectively; Sec. IV presents the fabrication, measurement, and test results of the cold model; Sec. V presents the multiphysics analysis; and the beam-loading effect and coupler design are discussed in Sec. VI.

\section{BEAM DYNAMICS DESIGN}

Several requirements constrain the beam dynamics design. First, the high current of $50 \mathrm{~mA}$ implies a strong space charge effect, which will adversely affect the beam properties and transmission. Second, because of cw operation, the intervane voltage is restricted to only $60 \mathrm{kV}$ to reduce power consumption and sparking risk. However, this will weaken the focusing force and lengthen the RFQ. Third, the large aperture of the RFQ means a large transverse acceptance and a high quality factor of the cavity, but both the RFQ length and beam transmission will

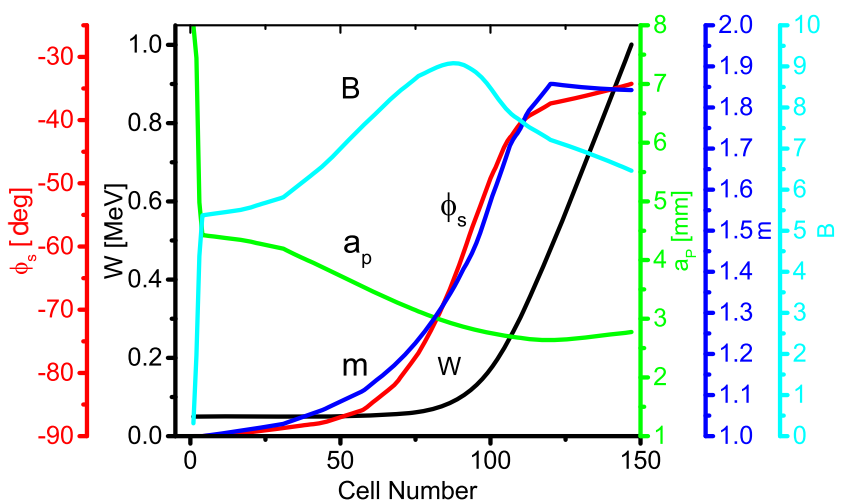

FIG. 2. RFQ design parameters after optimization.

be affected. Finally, beam losses, particularly at higher energies, need to be kept as low as possible, in order to mitigate the deuteron breakup reaction that generates neutrons and leads to radioactivation.

Because of restrictions of space and power consumption, we want the RFQ length to be as short as possible while ensuring the required beam quality and acceptable transmission. This can be done by changing the radial focusing strength $B$ from constant to variable along the RFQ and adjusting the modulation factor $m$ and synchronous phase $\phi_{s}$. First, increasing $B$ from the entrance to the gentle buncher section, as the cyan line shows in Fig. 2, can strengthen the external focusing force, thereby reducing the envelope growth. On the other hand, decreasing $B$ from the gentle buncher section to the exit avoids the beam being overfocused and increases the accelerating efficiency, which shortens the RFQ length. As shown in Fig. 3, the beam envelope and emittance growth are significantly reduced by this optimization, compared to the original design given by PARMTEQM [14].

Second, the modulation factor and synchronous phase should be adjusted. To ensure a wide stable region for the phase motion and to decrease longitudinal beam losses, both parameters are increased slowly from the entrance at cell 0 to cell 60, as the blue and red lines show in Fig. 2.

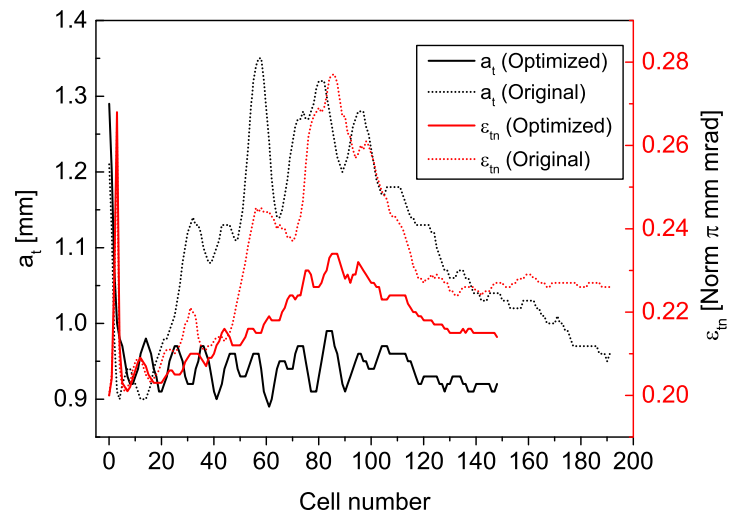

FIG. 3. Beam envelope and emittance of the original and optimized designs. 




FIG. 4. Comparison of the transverse and longitudinal limiting current of the original and optimized designs.

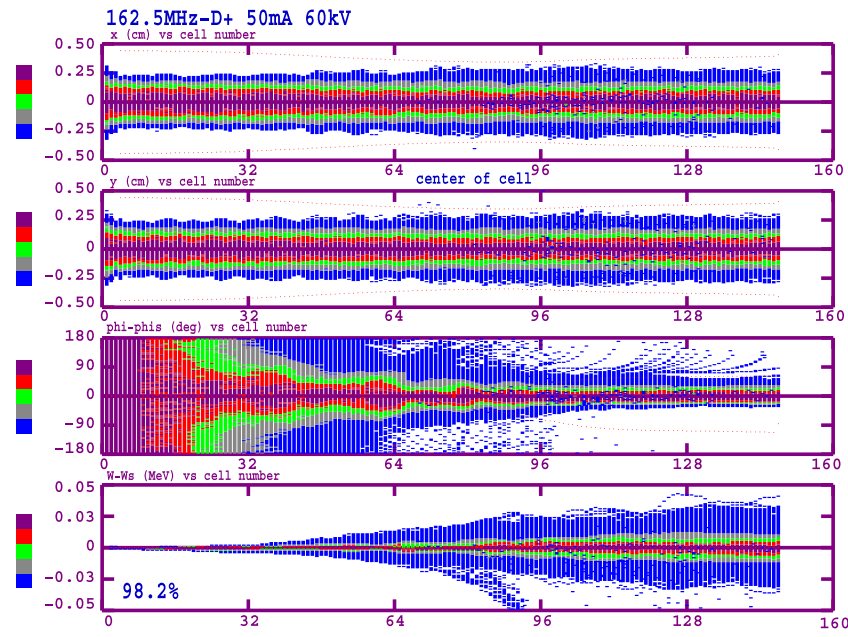

FIG. 5. Beam transmission along the RFQ. Plots from top to bottom are the beam profiles in the $x$ and $y$ planes and phase and energy spectrums, respectively.

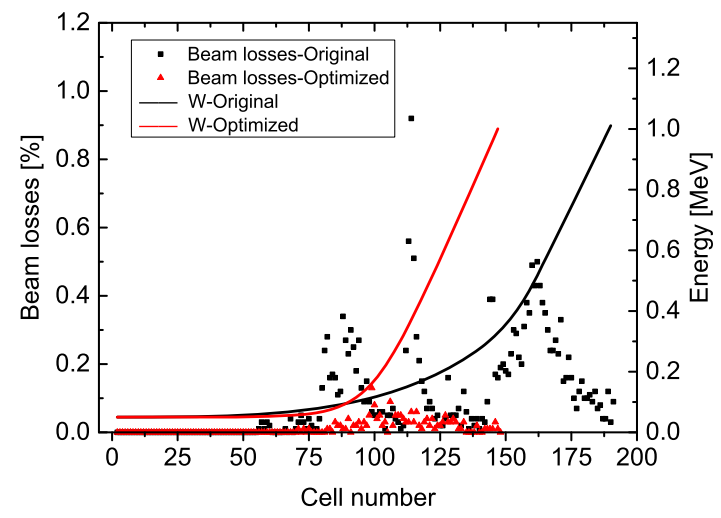

FIG. 6. The beam losses and energy change with a cell number in the original and optimized designs.

Then they are increased at a faster rate so that the longitudinal bunching force increases as fast as the transverse focusing force. Meanwhile, the longitudinal phase advance increases along with $m$ and $\phi_{s}$. According to
TABLE I. Design parameters of the deuteron RFQ.

\begin{tabular}{lc}
\hline \hline Parameter & Value \\
\hline Particle & Deuteron \\
Frequency [MHz] & 162.5 \\
Beam current [mA] & 50 \\
Beam duty factor [\%] & 100 \\
Intervane voltage [kV] & 60 \\
Input energy [MeV] & 0.05 \\
Output energy [MeV] & 1.01 \\
Minimum aperture radius [mm] & 2.63 \\
Average aperture radius [mm] & 3.88 \\
Vane length [m] & 1.81 \\
Synchronous phase & $-90^{\circ}$ \\
Modulation factor $-34^{\circ}$ \\
Input transverse emittance & $1-1.86$ \\
$\quad$ [ $\pi$ mm mrad] (normalized, rms) & 0.20 \\
Output transverse emittance & \\
$\quad$ [ $\pi$ mm mrad] (normalized, rms) & 0.22 \\
Output longitudinal emittance [MeV deg] & \\
$\quad$ (unnormalized, rms) & 0.12 \\
Maximum peak surface electric field [MV/m] & 22.74 \\
Kilpatrick coefficient & 1.67 \\
Transmission efficiency (PARMTEQM) [\%] & 98.2 \\
Transmission efficiency (TOUTATIS) [\%] & 98.6 \\
Acceleration efficiency (TOUTATIS) [\%] & 98.2 \\
\hline \hline
\end{tabular}

the limiting current formulas [15], zero current phase advance is also positively related to the limiting current. Therefore, in the gentle buncher and the acceleration section, the longitudinal current limit is improved (larger than the 50-mA design current), as shown in Fig. 4. This helps to bunch the beam more quickly and further shorten the RFQ length. Overall, by optimizing $B, m$, and $\phi_{s}$, we have ensured good beam quality while shortening the RFQ length. The simulation results of the optimized beam transmission are shown in Fig. 5.

The deuteron breakup reaction is also a concern for our RFQ, as this can generate neutrons and lead to radioactivation. The threshold energy of this reaction is $100 \mathrm{keV}$, so the beam losses at a high energy should be minimized. As shown in Fig. 6, the beam losses after optimization have been significantly reduced, especially at energies above $100 \mathrm{keV}$. This can greatly reduce the potential for deuteron breakup reactions. The final design parameters of this RFQ are summarized in Table I [16].

\section{RF STRUCTURE DESIGN}

\section{A. Choice of rf structure}

The four-vane and four-rod structures are the two most common candidates for RFQs. Although both of these would be appropriate to operate at the target frequency, the four-vane structure has a much lower power density and a higher quality factor and thus is more suitable for cw mode operation than the four-rod structure. However, with the 


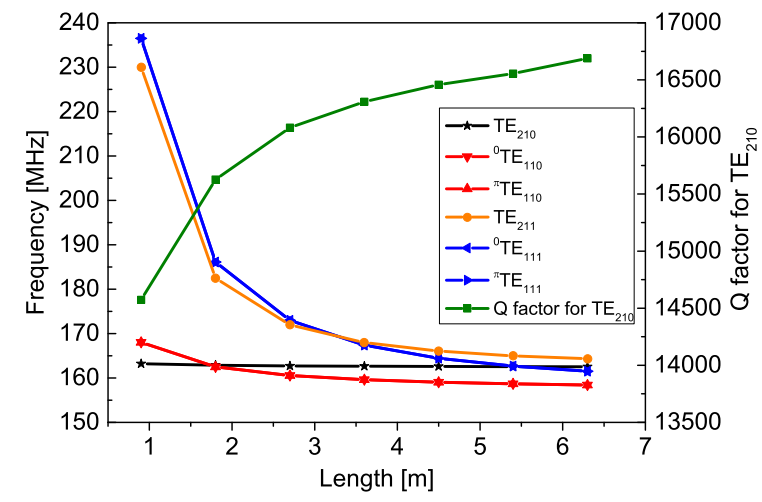

FIG. 7. Mode frequencies and quality factor for the $\mathrm{TE}_{210}$ mode as a function of the four-vane RFQ length.

four-vane RFQ, different resonance modes are mixed together, depending on the cavity cross section and the RFQ length. The simulation results plotted in Fig. 7 show how the first six mode frequencies and the quality factor for the operating quadrupole mode $\left(\mathrm{TE}_{210}\right)$ change with the RFQ length. With increasing length, the $\mathrm{TE}_{210}$ mode remains at approximately $162.5 \mathrm{MHz}$, whereas the other modes decrease and the quality factor increases. By utilizing this variation, RFQs with particular lengths (such as $2 \lambda$ or $4 \lambda$ ) have a relatively large mode separation between the operating $\mathrm{TE}_{210}$ mode and the dipole modes [17]. For a short RFQ such as our 1.809-m design, however, the frequency difference between the operating $\mathrm{TE}_{210}$ mode and the two $\mathrm{TE}_{110}$ modes is less than $0.25 \mathrm{MHz}$. Based on the experience of our cold model experiment, the error of machining and assembling, as well as material deformation, can cause a frequency shift of up to $0.3 \mathrm{MHz}$. This means that there is a risk that the quadrupole field would not be excited stably and successfully, so additional methods should be used to increase the mode separation.

The common method is to introduce $\pi$-mode stabilizing rods or dipole rods to the cavity, but this brings many new problems: Too many $\pi$-mode stabilizing rods in the RFQ cavity may increase the structural complexity and the risk of vacuum leaks; dipole rods will produce field ripples along the longitudinal directions and are easy to burn out in the $\mathrm{cw}$ mode due to the difficulty in cooling. Another method is cutting magnetic coupling windows into the vanes. This increases the volume of the empty cavity and allows the magnetic field in each quadrant to couple together through the vane windows, thereby decreasing mode frequencies. As dipole and quadrupole modes have different magnetic field distributions, their magnetic coupling situations are different, resulting in different frequency shifts and therefore separation of the modes. However, the magnetic field induces a surface current around the coupling windows, so at the same intervane voltage the power loss of a window-type RFQ is higher than that of a four-vane RFQ but still much lower than that of a four-rod RFQ. Ultimately, we chose the compact window-type structure and optimized the window dimensions to decrease the power loss and the electric field fluctuation.

Several software tools can be used for electromagnetic simulation. For our RFQ structure design, we primarily used CST MWS [18] and then we verified the final results using ANSYS EM [19].

\section{B. Optimization of magnetic coupling windows}

According to the principle mentioned before, adjusting the dimensions of the coupling windows will affect the magnetic field distribution, powerfully influencing the rf

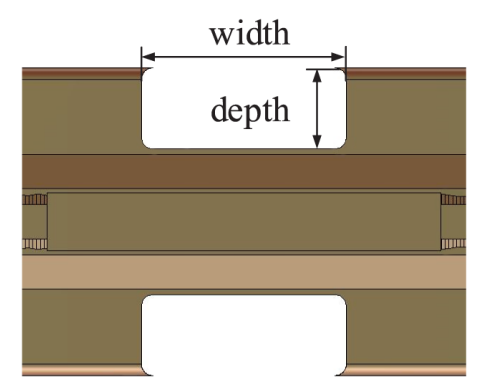

FIG. 8. Parameters of the coupling window.

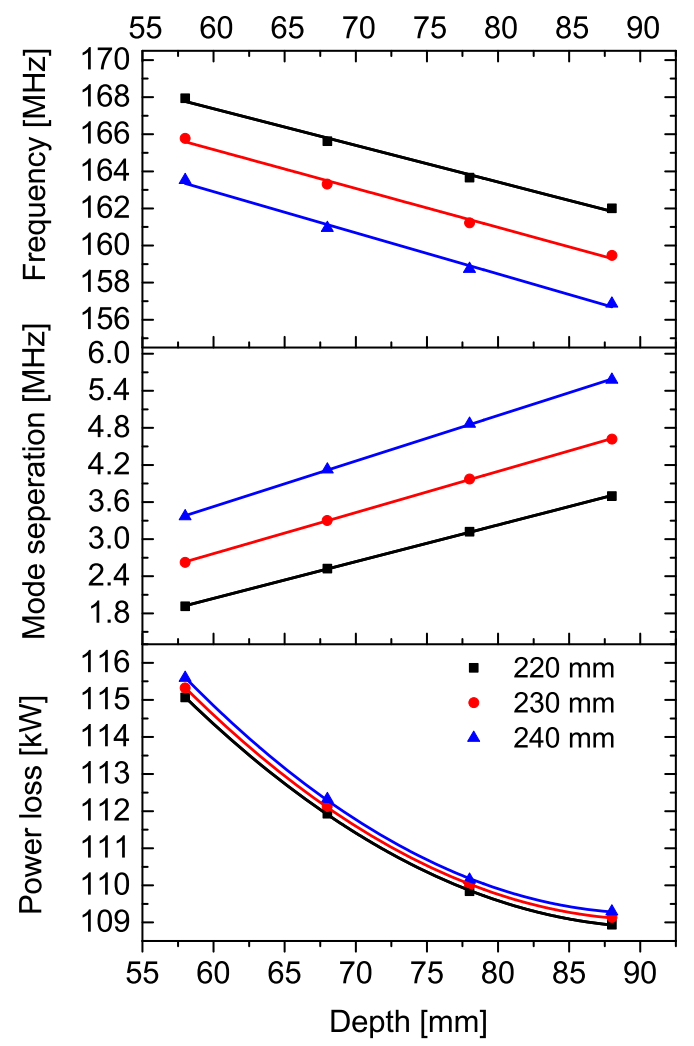

FIG. 9. Evaluation of $\mathrm{TE}_{210}$, mode separation between $\mathrm{TE}_{210}$ and ${ }^{0} \mathrm{TE}_{110}$, and power loss as a function of the depth for three width values. The stored energy of the RFQ cavity remains $1 \mathrm{~J}$ during the simulation. 
TABLE II. The first five mode frequencies of the window-type RFQ.

\begin{tabular}{lc}
\hline \hline Mode & Frequency [MHz] \\
\hline $\mathrm{TE}_{210}$ & 162.003 \\
${ }^{0} \mathrm{TE}_{110}$ & 165.700 \\
$\mathrm{TE}_{211}$ & 179.313 \\
${ }^{\pi} \mathrm{TE}_{110}$ & 179.825 \\
${ }^{0} \mathrm{TE}_{111}$ & 182.501 \\
\hline \hline
\end{tabular}

performance of the RFQ [20]. For our initial simulations and the cold model, we used a rectangular window, as shown in Fig. 8, so that the window area changes linearly with the width and depth. Figure 9 shows the variation of frequency, mode separation between the quadruple mode $\left(\mathrm{TE}_{210}\right)$ and the nearest dipole mode $\left({ }^{0} \mathrm{TE}_{110}\right)$, and power loss with window depth for three width values. As can be seen in it, increasing the depth and width leads to a stronger magnetic coupling and linearly reduces the frequency and increases the mode separation. Power loss is much more sensitive to changes in the depth than to changes in the width. As the magnetic field decreases rapidly from the cavity wall to the center axis, increasing the window depth makes little difference to the magnetic flux through the window, but the increased surface area around the window leads to a reduced surface current density, and the result is a net decrease in power loss. These relationships indicate that the coupling windows need to be as deep as possible to get a lower power loss and larger mode separation. However, their depth is also limited by the cooling channels and the mechanical strength. For our design, the window width and depth were set to 220 and $88 \mathrm{~mm}$, respectively, to achieve the designed frequency and a mode separation of $3 \mathrm{MHz}$. Table II lists the first five mode frequencies of the windowtype RFQ with these parameters. Unlike the modes of the four-vane RFQ, the quadrupole mode $\left(\mathrm{TE}_{210}\right)$ becomes the lowest mode, followed by one of the dipole modes $\left({ }^{0} \mathrm{TE}_{110}\right)$, yet the other dipole mode $\left({ }^{\pi} \mathrm{TE}_{110}\right)$ is quite high due to the asymmetrical magnetic coupling windows.

As shown in Fig. 10, two different shapes of coupling window have been considered, and the simulated results are listed in Table III. To compare results at the same frequency, the width of the elliptical window was changed to $266 \mathrm{~mm}$, while the other dimensions remained

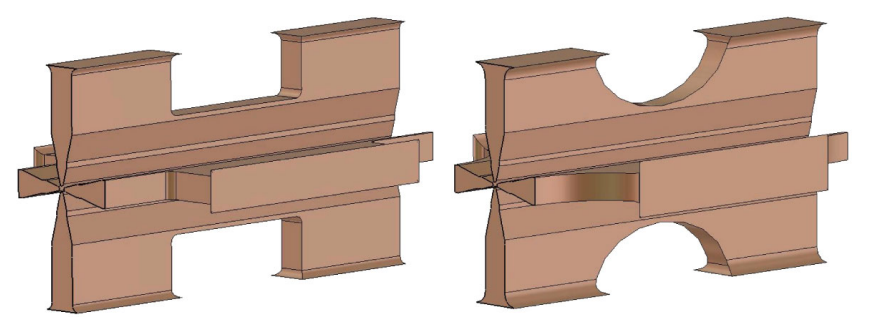

FIG. 10. Rectangular window and elliptical window.
TABLE III. Characteristics of two different window shapes.

\begin{tabular}{lcc}
\hline \hline Window shape & $\begin{array}{c}\text { Rectangular } \\
\text { window }\end{array}$ & $\begin{array}{c}\text { Elliptical } \\
\text { window }\end{array}$ \\
\hline Frequency [MHz] & 161.984 & 161.969 \\
Width [mm] & 220 & 266 \\
Depth [mm] & 88 & 88 \\
Window area [mm $\left.{ }^{2}\right]$ & 19360 & 18385 \\
Cavity radius [mm] & 170 & 170 \\
Mode separation $[\mathrm{MHz}]$ & 3.713 & 4.085 \\
Peak power density $\left[\mathrm{W} / \mathrm{m}^{2}\right]$ & $5.567 \times 10^{5}$ & $4.604 \times 10^{5}$ \\
Power loss [kW] & 49.0 & 42.7 \\
Quality factor & 9481 & 10159 \\
\hline \hline
\end{tabular}

unchanged. Compared to the rectangular window, the elliptical window provides a slightly larger mode separation with a smaller area and a lower peak power density at the corner of the windows, which leads to a lower power loss and a higher quality factor for the RFQ cavity. As shown in Fig. 11, each peak field along the RFQ corresponds to the location of a coupling window. The field unflatness due to the rectangular window is $\pm 0.5 \%$ (black dashed line), whereas that due to the elliptical window is $\pm 0.4 \%$ (red line). Also, the structure with the elliptical windows has better mechanical strength. Therefore, the final design will employ an elliptical window rather than the rectangular window used in the cold model.

\section{Optimization of modulated electric field}

Electric field flatness along the RFQ is one of the most important parameters of the structure. The introduction of vane modulations causes an uneven capacitance distribution along the RFQ, and the variable focusing strength exacerbates this unevenness. Adding modulations to the vanes changes the simulated field distribution curve from the red dotted line to the black dotted line in Fig. 12. The maximal field unflatness reached $\pm 6 \%$. This can be smoothed by changing the widths of the half windows in the two horizontal vanes at both cavity ends (just like the undercuts of a normal four-vane RFQ) as well as by

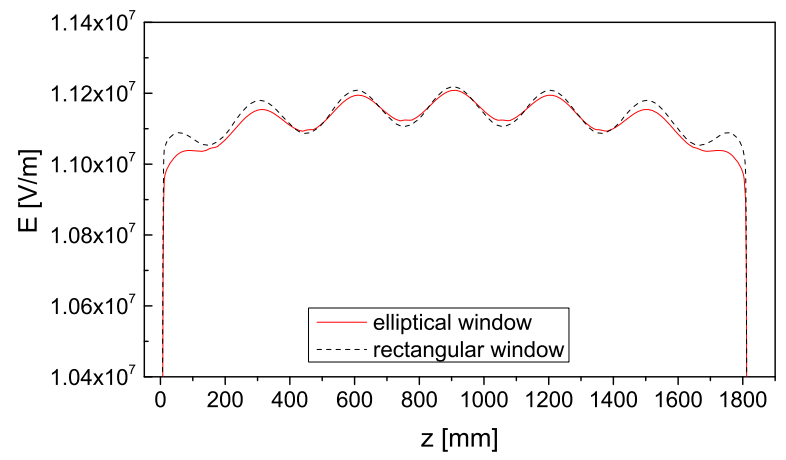

FIG. 11. Electric field comparison of two different window shapes. 


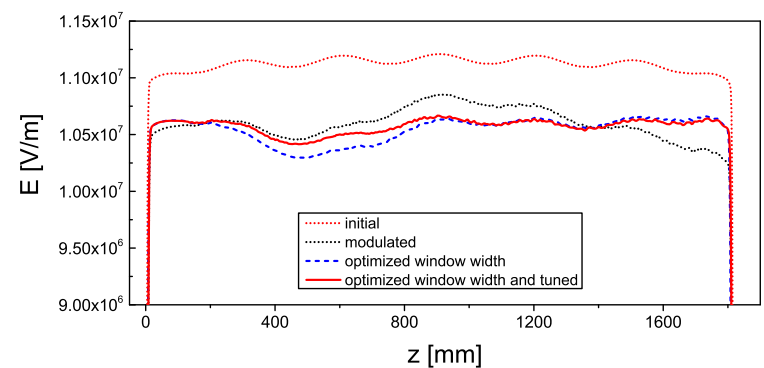

FIG. 12. The electric field along the RFQ before and after optimization.

inserting tuners. When the half-window widths at the entrance and exit are changed to 133.5 and $135 \mathrm{~mm}$, respectively (and the other window widths are changed to $258 \mathrm{~mm}$ ), the field unflatness is reduced to $\pm 2 \%$, as the blue dashed line shows in Fig. 12. After tuning with 28 60-mm-diameter tuners (see Fig. 1), the field unflatness is already reduced to less than $\pm 1 \%$, as the red line shows in Fig. 12. If all the tuners are inserted a maximal $60 \mathrm{~mm}$ deep inside the cavity, the maximum frequency tuning range can be up to $2.5 \mathrm{MHz}$, which is sufficient for tuning the frequency to the target value.

\section{Comparison with normal four-vane RFQ}

To better understand the rf performance of the window-type RFQ, we summarized the parameters of this RFQ and simulated a normal four-vane RFQ without stabilizing rods as a contrast. The results are listed in Table IV. For a given frequency and length, the windowtype RFQ has a smaller cavity cross section and a better mode separation than a normal four-vane RFQ but at the cost of a $25 \%$ drop in the quality factor and a $44 \%$ higher power loss.

Another difference between the window-type RFQ and the four-vane RFQ lies in the field distribution in the gaps between the end plates and the vanes. As shown in Fig. 13, there is an additional longitudinal field component in these

TABLE IV. Comparison of a window-type RFQ and a normal four-vane RFQ.

\begin{tabular}{lcc}
\hline \hline Parameter & $\begin{array}{c}\text { Window-type } \\
\text { RFQ }\end{array}$ & $\begin{array}{c}\text { Four-vane } \\
\text { RFQ }\end{array}$ \\
\hline Frequency [MHz] & 162.423 & 162.404 \\
Window width [mm] & $133.5 / 258 / 135$ & $\ldots$ \\
Window depth [mm] & 88 & $\ldots$ \\
Mode separation [MHz] & 3.400 & 0.583 \\
Cavity radius [mm] & 170 & 183 \\
Length of the vanes $[\mathrm{m}]$ & 1.809 & 1.809 \\
Quality factor & 10212 & 13685 \\
Power loss [kW] & 42.492 & 29.612 \\
Peak power density $\left[\mathrm{W} / \mathrm{m}^{2}\right]$ & $3.846 \times 10^{5}$ & $2.691 \times 10^{5}$ \\
Specific shunt impedance $[\mathrm{k} \Omega \mathrm{m}]$ & 153.262 & 219.924 \\
\hline \hline
\end{tabular}



FIG. 13. On-axis longitudinal fields along the four-vane and window-type RFQs.

gaps for the window-type RFQ, which is due to the asymmetry at both cavity ends caused by the stagger windows in adjacent vanes (see Figs. 1 or 10). The beam dynamics simulations using TRACEWIN [21] indicate that this field component causes an energy spread of $4 \%$ for input beams. Because our beam dynamics was designed with a high tolerance for energy spread, this field component leads only to a slight change of the transmission and acceleration efficiencies from $99.6 \%$ and $98.4 \%$ to $99.5 \%$ and $98.7 \%$, respectively. Similar results also have been presented in Ref. [22].

\section{E. Study of the equivalent circuit model}

The equivalent circuit model helps us to understand the impact of the magnetic coupling windows. For normal fourvane and four-rod RFQs, the equivalent circuit has already been carefully studied $[23,24]$. The quadrupole resonant frequency of a four-vane RFQ circuit model is

$$
f_{4 \mathrm{vane}}=\frac{1}{2 \pi \sqrt{L_{4 \mathrm{vane}} C}},
$$

where $C(\mathrm{~F} / \mathrm{m})$ is the total equivalent capacitance per quadrant per unit length and $L_{4 \mathrm{vane}}(\mathrm{H} * \mathrm{~m})$ is the equivalent inductance of each quadrant, related to the crosssectional area of the cavity. Both of them can be estimated by semiempirical formulas [25]. Now we divide the inductance $L_{4 v a n e}$ into two parts: the cavity walls as inductance $L_{1}$ and the vane as inductance $L_{2}$, so that the total inductance is $L_{4 \mathrm{vane}}=L_{1}+2 L_{2}$. The ratio of $L_{1}$ and $L_{4 \mathrm{vane}}$ is related to the cavity shape. Based on our experience, good results can be obtained when choosing the ratio of 0.85 for our octagonal cavity.

Analyzing the simulated surface currents shown in Fig. 14, we construct the window-type RFQ as the resonant circuit shown in Fig. 15(a), where $C_{0}$ represents the capacitance between two opposite vanes, through which there is a current flow only in dipole modes. For analyzing the quadrupole mode, it is more convenient to use the circuit per section per quadrant for the calculation, as shown in Fig. 15(b) [26]. Based on Kirchhoff's laws, the resonant frequency is 


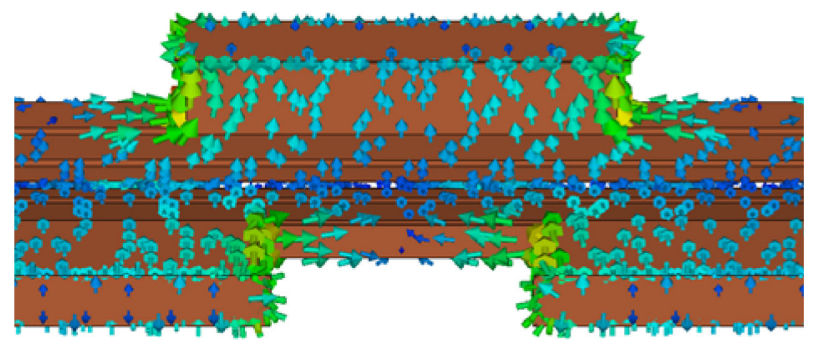

FIG. 14. The surface current of a window-type RFQ in one quadrant.

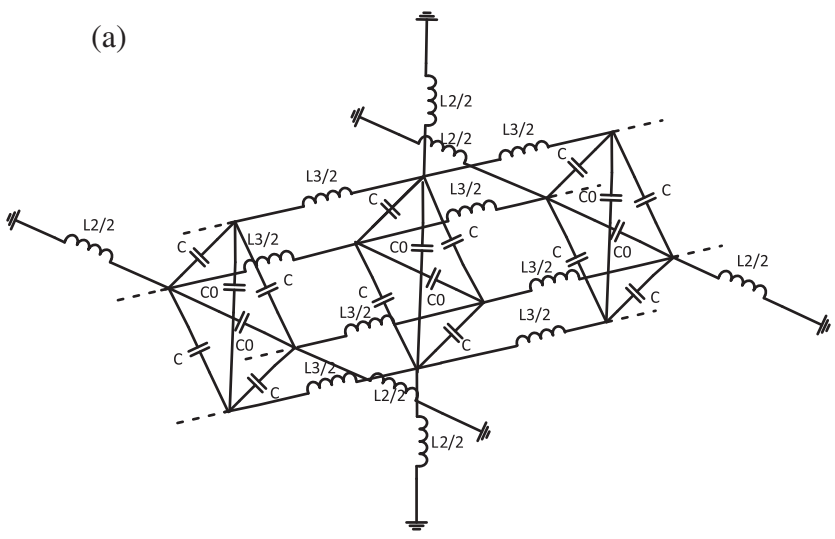

(b)

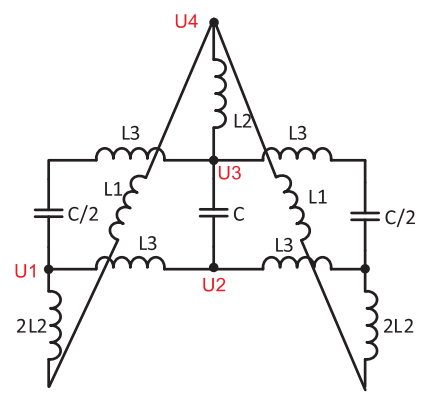

FIG. 15. Equivalent circuit of a window-type RFQ. (a) The whole circuit without equivalent inductance $L_{1}$. (b) The simplified circuit per section per quadrant.

$$
f=\frac{1}{2 \pi \sqrt{\left(L_{1}+4 L_{2}+L_{3} / 2\right) C}}
$$

where $L_{3}$ is the longitudinal equivalent inductance and $4 L_{2}+L_{3} / 2$ is the inductance of the coupling window. It can be approximated using the formula for a single-turn solenoid of cross-sectional area $A$ [27]:

$$
4 L_{2}+L_{3} / 2=\mu_{0} A=\mu_{0}\left(w d+\frac{1}{4} w^{2}-\frac{1}{2} d^{2}\right)
$$

where $w$ is half of the window width and $d$ is the window depth. The second and third terms are empirical corrections, arising from the nonuniform distribution of the magnetic field across the window. Notice that the corrections do not apply in the case $d>w$ (although this rarely happens); otherwise, the variation trend of frequency along with $d$ will change. For a given dimension, a normal four-vane RFQ and the window-type RFQ have the same cavity wall inductance $L_{1}$ and total capacitance $C$. Thus, the quadrupole resonant frequency of the window-type RFQ is

$$
f_{\text {window }}=\frac{1}{2 \pi \sqrt{\left[0.85 L_{4 \text { vane }}+\mu_{0}\left(w d+\frac{1}{4} w^{2}-\frac{1}{2} d^{2}\right)\right] C}} .
$$

The equations above quantitatively show that the frequency of a window-type RFQ is much lower than that of a four-vane RFQ due to the introduction of the longitudinal inductance, and the relation that the larger the window dimension, the lower the frequency is also consistent with the simulated result shown in Fig. 9. For our rectangular window-type RFQ, if $w=220 / 2$ and $d=88 \mathrm{~mm}$, the calculated frequency is $f_{\text {window }}=164.230 \mathrm{MHz}$, which agrees with the simulated result $(162.003 \mathrm{MHz})$. Using the same parameters without $w$ and $d$, we find that $f_{4 \text { vane }}=186.631 \mathrm{MHz}$, which is also close to the simulated result (184.854 MHz).

\section{COLD MODEL EXPERIMENTS}

\section{A. Fabrication and measurement}

Our first cold model was designed with variable windows and was useful to validate the relation of the frequency and mode separation to the window dimension. However, because assembling the adjustable components led to a poor electrical contact, the cavity quality factor was very low. A second model was constructed with fixed-size windows $(240 \times 80 \mathrm{~mm})$, vane modulations, and tuners. As the left-hand two photos show in Fig. 16, the whole model was divided into four cavity walls and four vanes for manufacturing, following the design of the planned final copper cavity. Then the four vanes were installed in four steel frameworks for positioning, as the right-hand photo shows in Fig. 16. We preassembled the cavity with the vanes still unmodulated and found that the frequency was very sensitive to assembling errors and material deformation. This is because, to leave an adequate margin for modulation processing, the vane tip radius was far larger than the design value and the distance between adjacent vanes was too small.

According to the beam dynamics design, the focusing strength, related to the average radius of each cell, is not a constant, resulting in a varying vane tip radius along the RFQ. Therefore, a ball-end milling tool was used to process the vane modulation. Assembling the cavity again, we measured and adjusted the distances between each quadrant adjacent vanes (dI, dII, dIII, and dIV) and between opposite 


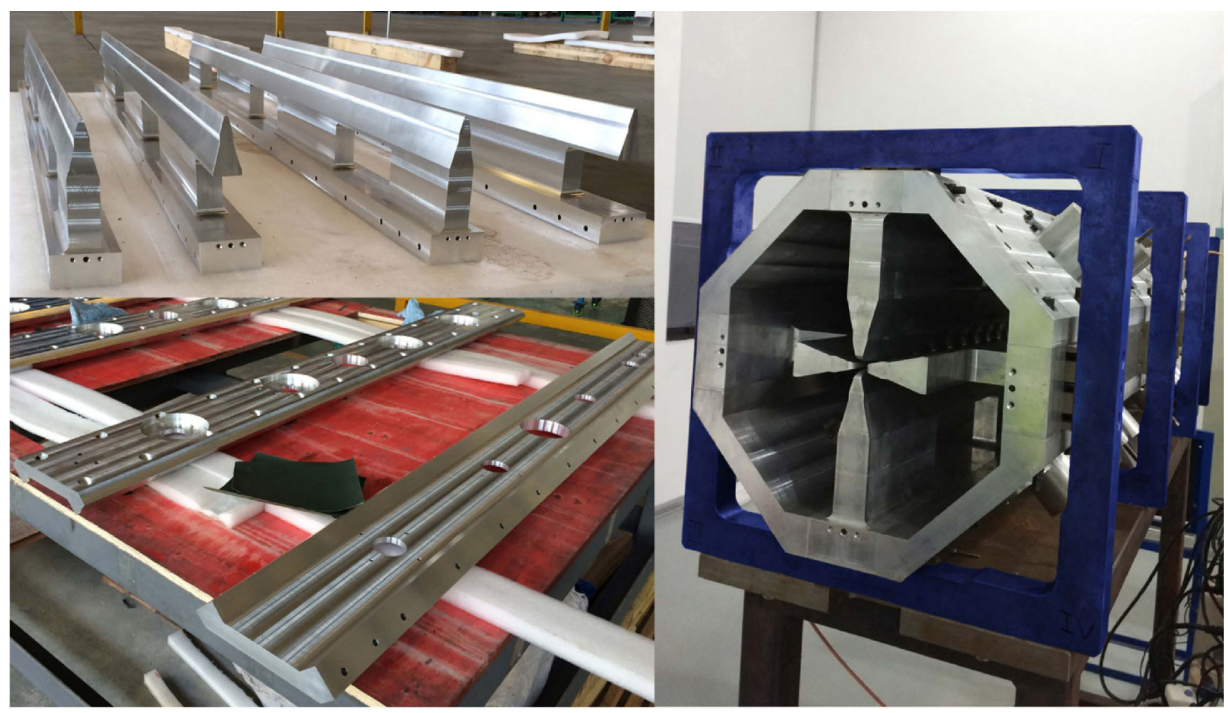

FIG. 16. The vanes (before processing the modulations), cavity walls, and assembly (without end plates) of the cold model.
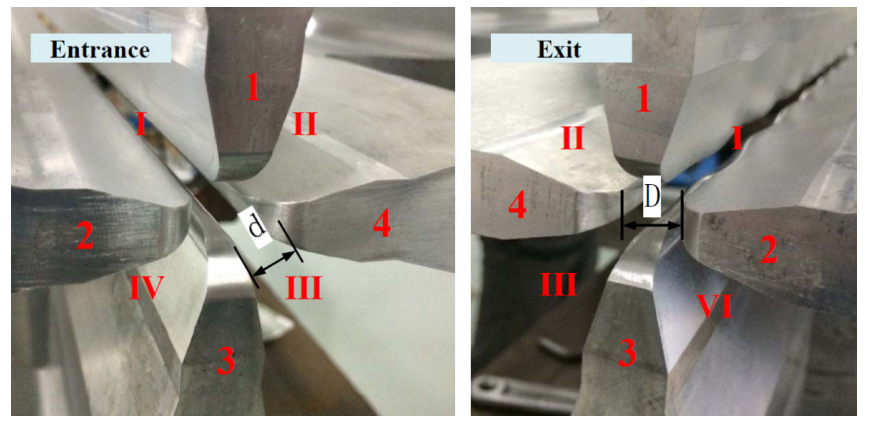

FIG. 17. The measurement of the cold model.

vanes (DH and DV) and the horizontal and vertical cavity diameters ( $\mathrm{LH}$ and LV, respectively) at the entrance and exit, as shown in Fig. 17. Results listed in Table V indicate that most measured parameters were close to the design values. The average error was $33 \mu \mathrm{m}$.

TABLE V. Comparison of the simulated and measured parameters.

\begin{tabular}{lccccc}
\hline \hline & \multicolumn{2}{c}{ Entrance } & & \multicolumn{2}{c}{ Exit } \\
\cline { 2 - 3 } \cline { 5 - 6 } Parameter & $\begin{array}{c}\text { Simulated } \\
{[\mathrm{mm}]}\end{array}$ & $\begin{array}{c}\text { Measured } \\
{[\mathrm{mm}]}\end{array}$ & & $\begin{array}{c}\text { Simulated } \\
{[\mathrm{mm}]}\end{array}$ & $\begin{array}{c}\text { Measured } \\
{[\mathrm{mm}]}\end{array}$ \\
\hline dI & 3.98 & 4.01 & & 4.31 & 4.29 \\
dII & & 4.02 & & 4.38 \\
dIII & & 4.01 & & 4.33 \\
dIV & & 3.91 & & 4.33 \\
DH & 8.17 & $\approx 8.17$ & & 8.85 & 8.90 \\
DV & & & & 8.80 \\
LH & 312.00 & 311.98 & & 312.00 & 311.98 \\
LV & & 311.94 & & 312.05 \\
\hline \hline
\end{tabular}

\section{B. rf measurement and tuning for the cold model}

The rf parameters before tuning were measured by two pickups in the transmission mode with very weak coupling, in order to obtain the loaded quality factor approximately equal to the unloaded one. As listed in Table VI, the obtained results were all very close to the simulated values. The operating frequency deviation was $-0.299 \mathrm{MHz}$, and the quality factor deviation was only -831 .

The field measurement adopted the common bead-pull perturbation method and was performed by a computerbased servomotor drive system and a network analyzer. Using a $0.325-\mathrm{mm}$-diameter nylon wire to guide a $4-\mathrm{mm}$ diameter dielectric bead, we measured the electric field $15 \mathrm{~mm}$ distant from the aperture center in each quadrant. The field unflatness and the asymmetry of four quadrants were calculated according to the following two formulas, respectively:

TABLE VI. Comparison of the simulated and measured parameters of the cold model.

\begin{tabular}{|c|c|c|c|c|c|c|}
\hline \multirow[b]{2}{*}{ Mode } & \multicolumn{2}{|c|}{ Simulated } & \multicolumn{4}{|c|}{ Measured } \\
\hline & $\begin{array}{c}\text { Frequency } \\
{[\mathrm{MHz}]}\end{array}$ & $\begin{array}{c}\text { Unloaded } \\
\text { quality } \\
\text { factor }^{\mathrm{a}}\end{array}$ & $\begin{array}{c}\text { Frequency } \\
{[\mathrm{MHz}]}\end{array}$ & $\begin{array}{c}\text { Loaded } \\
\text { quality } \\
\text { factor }^{\mathrm{a}}\end{array}$ & $\begin{array}{c}S_{21} \\
{[\mathrm{~dB}]}\end{array}$ & $\begin{array}{c}S_{11} \\
{[\mathrm{~dB}]}\end{array}$ \\
\hline $\mathrm{TE}_{210}$ & 161.978 & 5614 & 161.680 & 4783 & -26.8 & -0.59 \\
\hline${ }^{0} \mathrm{TE}_{110}$ & 168.229 & 6311 & 167.982 & 5347 & -28.2 & -0.27 \\
\hline $\mathrm{TE}_{211}$ & 180.206 & 2730 & 180.438 & 2500 & -41.4 & -0.41 \\
\hline${ }^{\pi} \mathrm{TE}_{110}$ & 181.635 & 3733 & 180.174 & 3142 & -33.5 & -0.20 \\
\hline${ }^{0} \mathrm{TE}_{111}$ & 185.675 & 3042 & 185.958 & 2945 & -34.1 & -0.21 \\
\hline
\end{tabular}



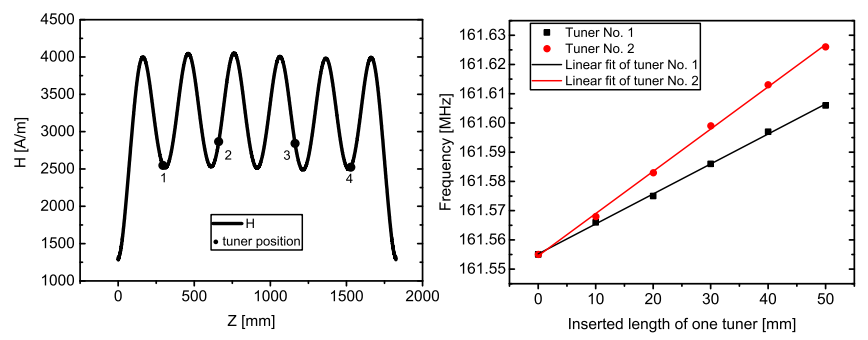

FIG. 18. The left-hand side shows the magnetic field along the RFQ and the tuner positions. The right-hand side shows the frequency shift as a function of the inserted depth of no. 1 and no. 2 tuners.

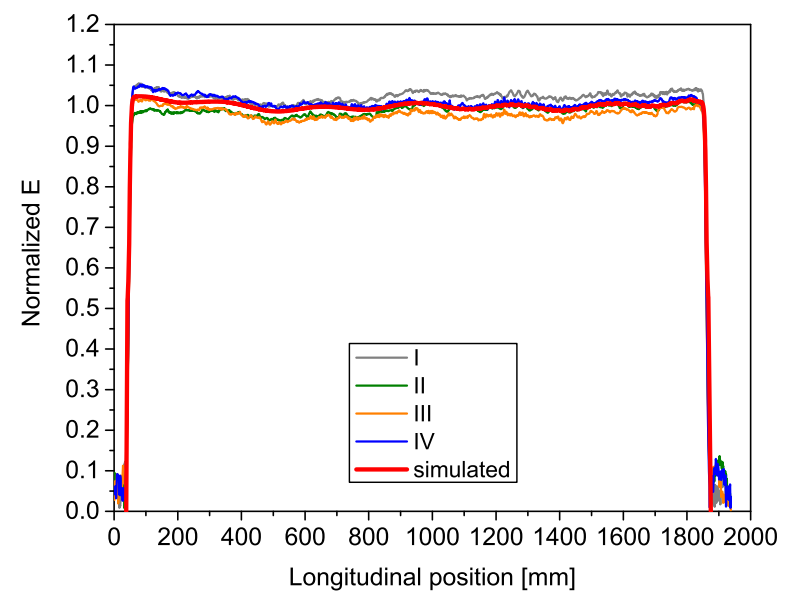

FIG. 19. Tuned electric field along the RFQ cold model for four quadrants. The simulated field is also included for comparison.



(a) Point

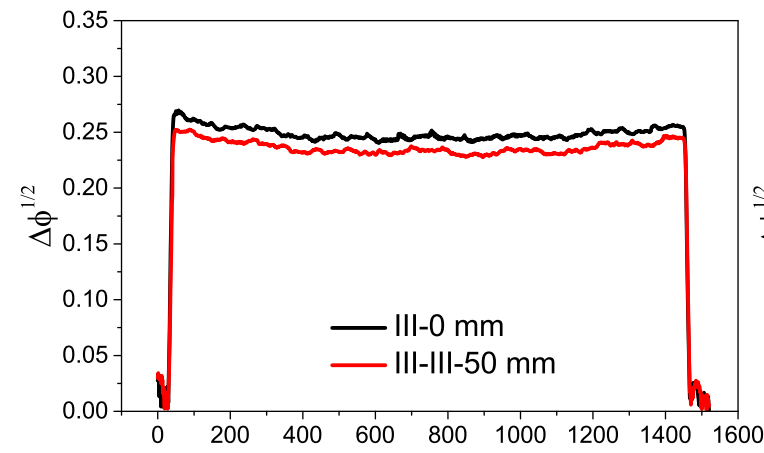

(c) Point

$$
\begin{gathered}
\text { unflatness }=\frac{E_{Q k}-\overline{E_{Q}}}{\overline{E_{Q}}} \times 100 \%, \\
\text { asymmetry }=\frac{E_{Q k}-\overline{E_{k}}}{\overline{E_{k}}} \times 100 \% .
\end{gathered}
$$

Here the subscript $Q(Q=\mathrm{I}, \mathrm{II}, \mathrm{III}, \mathrm{IV})$ is the quadrant label, and the $k(k=1,2,3, \ldots)$ is the point number that refers to different longitudinal positions along the cold model. Thus, $\overline{E_{Q}}$ is the average electric field of a quadrant, and $\overline{E_{k}}$ is the average of four quadrants' field at a longitudinal position. Because of material deformation and assembling errors, the measured maximal unflatness was nearly $7 \%$ and the average asymmetry of four quadrants reached $3.64 \%$, so tuning was necessary.

The cold model was equipped with four 50-mm-diameter tuners for each quadrant (in total, 16 tuners). For the window-type RFQ, it is worth noting that, because the magnetic field varies periodically with the coupling windows, tuners in different longitudinal positions have different tuning capabilities. Figure 18 shows the magnetic field values corresponding to the four tuner positions in one quadrant and the measured frequency shift caused by the inserted tuners in different positions. Because of the larger magnetic field at its location, tuner no. 2 has more powerful tuning capability than tuner no. 1 . The tuning sensitivity is approximately $1.0-1.5 \mathrm{kHz} / \mathrm{mm}$ for each tuner.

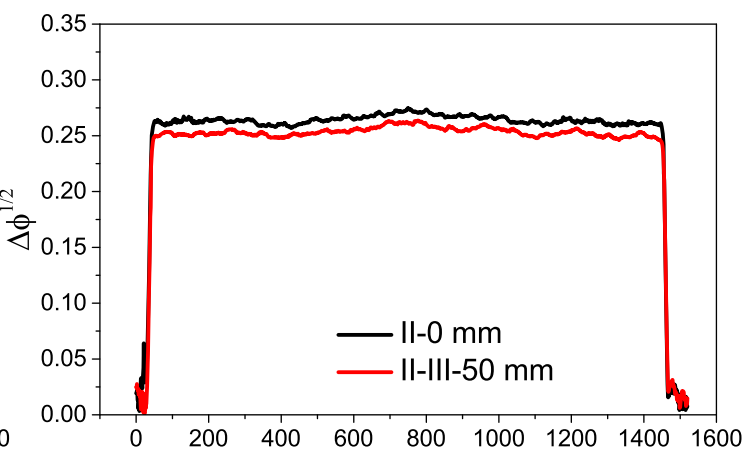

(b) Point

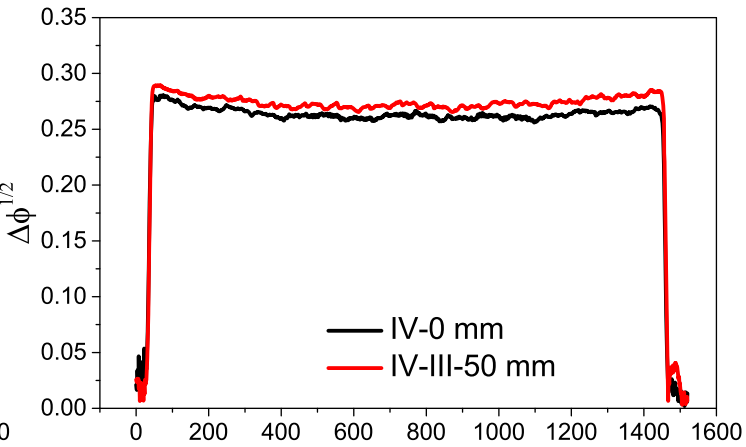

(d) Point

FIG. 20. The electric field of the four quadrants along the RFQ with all the tuners of the third quadrant inserted $50 \mathrm{~mm}$ into the cavity. The black line in each graph is the electric field without tuners for comparison. 


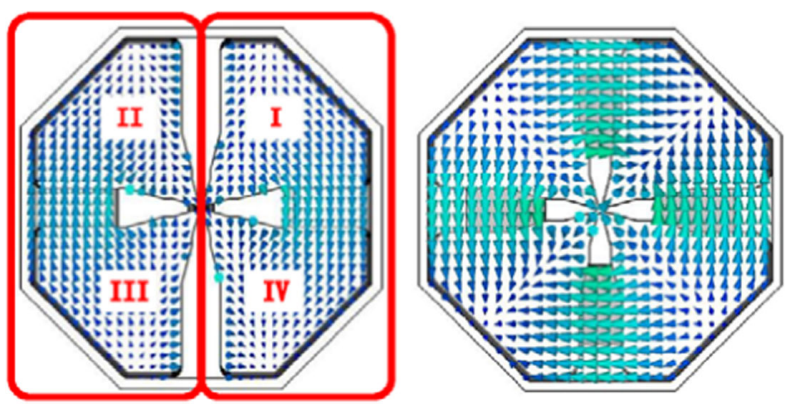

FIG. 21. The left-hand side shows the coupling effect between the quadrants, and the right-hand side shows the magnetic field of the normal four-vane RFQ at the cavity end.

During the tuning process, we first adjusted each tuner to get a flat field in each quadrant by analyzing the measured field distribution. Then, based on the average tuning sensitivity for the frequency, we moved all the tuners by the same distance, thereby adjusting the frequency to the target value while maintaining the field profile. As shown in Fig. 19, the maximal unflatness and the average asymmetry after tuning were reduced to $4 \%$ and $1.69 \%$, respectively [28]. Nonetheless, we realized that the tuners of the cold model were not sufficient for field tuning. Thus, as mentioned above, the diameter of the tuners has been enlarged to $60 \mathrm{~mm}$, and the number has been increased to 28 for the future copper cavity.

An interesting coupling effect between the quadrants on both sides of the horizontal vanes was found during the tuning process. To illustrate this effect, we inserted all the tuners of the third quadrant $50 \mathrm{~mm}$ deep into the cavity and observed how the field in all four quadrants changed. For a four-vane RFQ, we know from its tuning rule that the first quadrant field will drop as much as the third quadrant field will rise, whereas the second and fourth quadrant fields will not be affected. But for the window-type RFQ, it can be seen in Fig. 20 that both the third and adjacent second quadrant fields dropped, whereas the first and fourth quadrant fields rose. This is because, unlike the end cuts of the four-vane RFQ, the half windows of the window-type RFQ, which allow the magnetic field to pass through, exist only in the horizontal vanes' ends. This powerfully couples together the two quadrants on each side of the horizontal vanes, as shown in Fig. 21. In the near future, this coupling will be taken into account in a new tuning program for the copper cavity.

\section{Tolerance analysis for electric field unflatness}

Since the electric field measured after tuning is still not very smooth, it is necessary to analyze how this field fluctuation will affect the beam transmission. We used the measured field from the cold model as an example of a nonideal field and then multiplied the deviation of this measured field by scalar multiples to represent different
TABLE VII. The transmission and accelerating efficiency with different multiples of the field deviation.

\begin{tabular}{lccc}
\hline \hline $\begin{array}{l}\text { Multiple of } \\
\text { field deviation }\end{array}$ & $\begin{array}{c}\text { Field } \\
\text { unflatness [\%] }\end{array}$ & $\begin{array}{c}\text { Transmission } \\
\text { efficiency [\%] }\end{array}$ & $\begin{array}{c}\text { Acceleration } \\
\text { efficiency [\%] }\end{array}$ \\
\hline 0 & 0 & 99.1 & 98.8 \\
1 & \pm 4 & 98.6 & 98.3 \\
2 & \pm 8 & 97.6 & 97.2 \\
3 & \pm 12 & 95.0 & 94.3 \\
\hline \hline
\end{tabular}

degrees of unflatness. For example, multiple 0 is the original ideal field, multiple 1 is the measured field of the cold model, and multiple 2 means multiplying the measured field deviation by 2 . Then, because each vane potential affects the field in both adjacent quadrant fields, we define the conversion from field unflatness $E \%$ to vane potential $V$ as

$$
\begin{aligned}
& V_{1}=\frac{V_{0}}{2} \times\left(1+E_{\mathrm{I}} \%+E_{\mathrm{II}} \%\right), \\
& V_{2}=-\frac{V_{0}}{2} \times\left(1+E_{\mathrm{I}} \%+E_{\mathrm{IV}} \%\right), \\
& V_{3}=\frac{V_{0}}{2} \times\left(1+E_{\mathrm{III}} \%+E_{\mathrm{IV}} \%\right), \\
& V_{4}=-\frac{V_{0}}{2} \times\left(1+E_{\mathrm{III}} \%+E_{\mathrm{II}} \%\right),
\end{aligned}
$$

where $V_{0}=60 \mathrm{kV}$ is the ideal vane voltage and the labels of the four quadrants and the four vanes are consistent with those in Fig. 17. By importing the calculated vane potential to TOUTATIS [29], we simulated the beam transmission corresponding to these different degrees of unflatness. As shown in Table VII, as well as Figs. 22 and 23, increasing the field unflatness results in decreasing the transmission efficiency, output emittance growth, and beam profile oscillations. The maximum slip angle of the beam profile

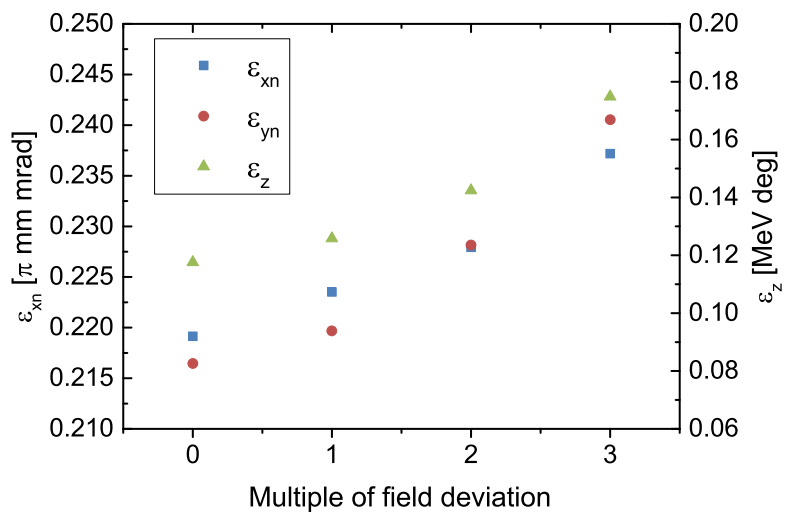

FIG. 22. Output transverse and longitudinal emittance at different multiples of the field deviation. 

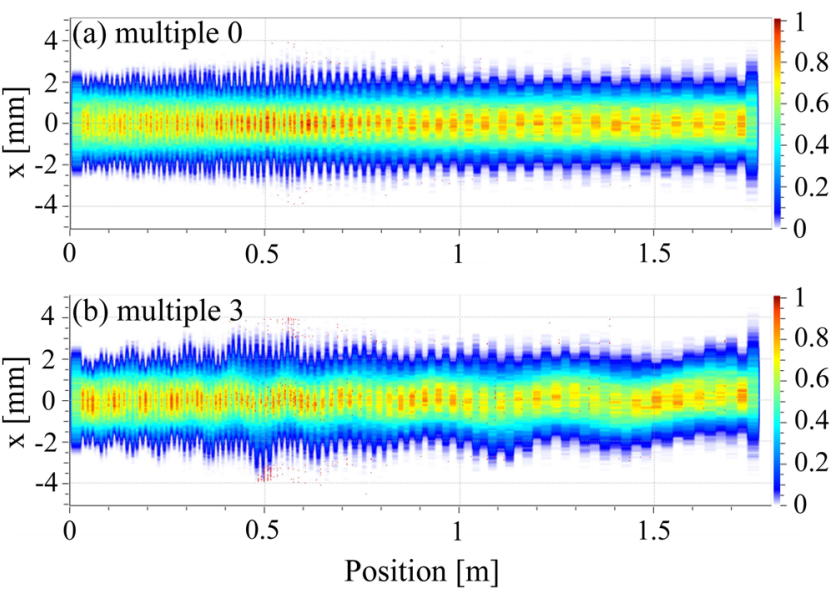

FIG. 23. Beam envelopes at (a) multiple 0 and (b) multiple 3.

for multiple 3 is approximately $0.5^{\circ}$. With the field unflatness within $\pm 12 \%$, the transmission efficiency of $95 \%$ and transverse emittance growth of $20 \%$ are acceptable for the 50 -mA deuteron beam. However, to ensure the stability of the beam transmission, to eliminate the beam halo, and to avoid an off-center beam, the electric field still needs to be as flat as possible.

\section{COOLING SYSTEM DESIGN}

For the cooling system design, we used both CST and ANSYS for an independent multiphysics analysis and compared the results. Each has a complete loop of coupled numerical studies, including electromagnetic, thermal, and mechanical analysis, as shown in Fig. 24. The surface current induced by the magnetic field produces $46.523 \mathrm{~kW}$ of thermal loss. Because of the magnetic field passing through, the power density is relatively high around the coupling windows, with the maxima located at the corners of the half windows, as shown in Fig. 25(a). This explains why the power loss of the horizontal vane is a little higher than that of the vertical vane in Fig. 25(b). Therefore, the coupling windows are the main concern in the cooling channel design.

At first, there was only one channel around each window, and the cooling was not effective enough, even when the channel diameter was increased to $14 \mathrm{~mm}$. In the new design, two connected channels are situated much closer to

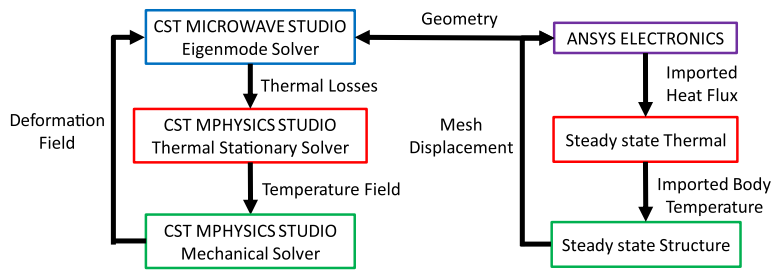

FIG. 24. Multiphysics scheme based on CST and ANSYS.

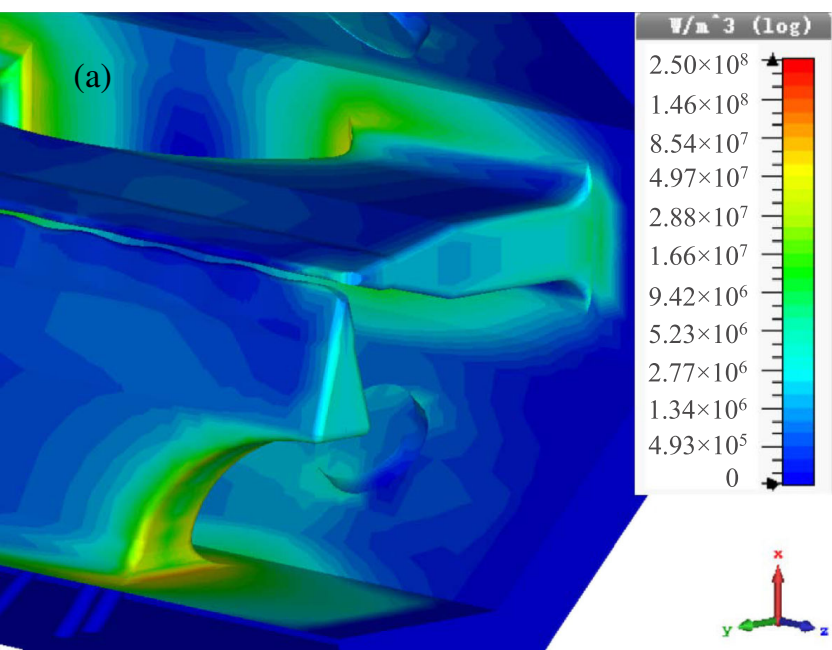

(b)

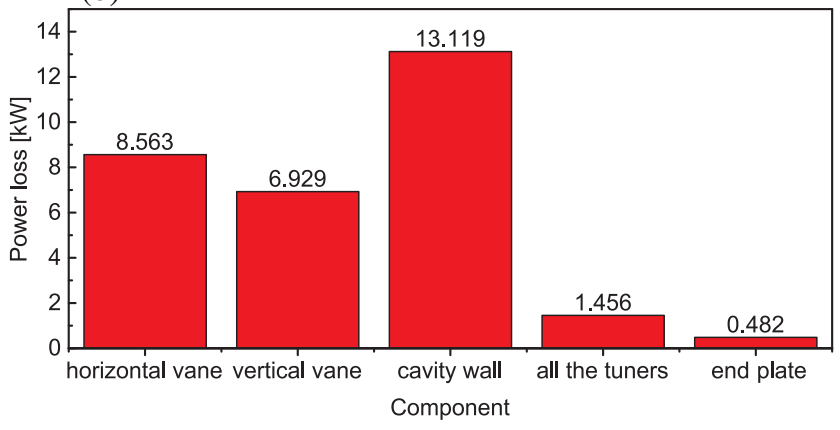

FIG. 25. (a) Power density and (b) power loss for RFQ components, with the intervane voltage normalized to $60 \mathrm{kV}$.

the window edges, as shown in Fig. 26, which significantly improves the cooling efficiency [30]. The window channel is $10 \mathrm{~mm}$ in diameter, and the vane channel is $8 \mathrm{~mm}$. The flow velocity of cooling water is conservatively set at $2.3 \mathrm{~m} / \mathrm{s}$. The water and the background temperature are considered to be 291 and $295 \mathrm{~K}$, respectively. To save computing time, we adopted theoretically calculated heat transfer coefficient values in the thermal analysis [31],

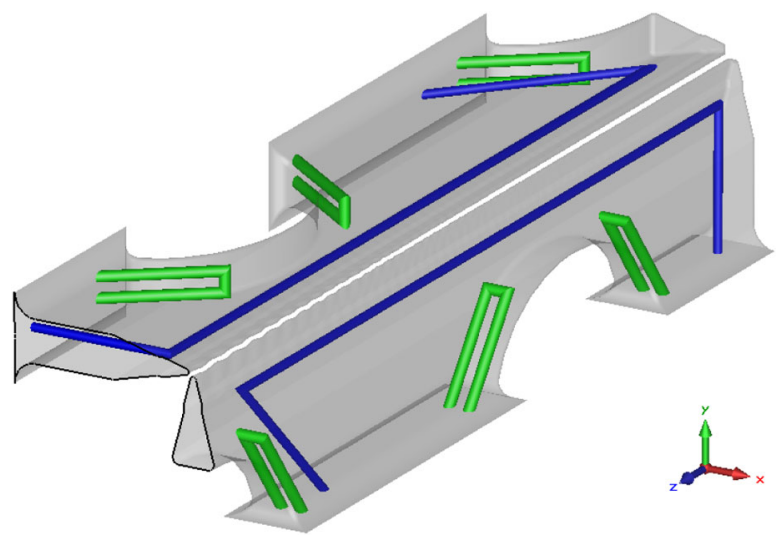

FIG. 26. The cooling channel design. 


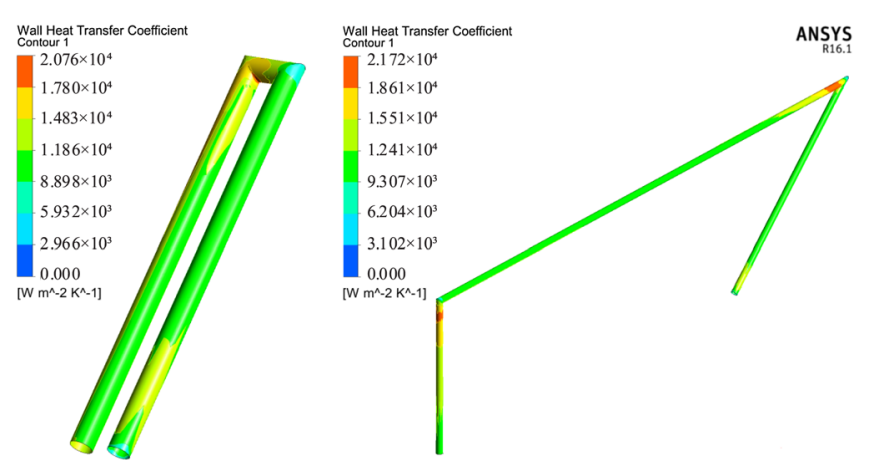

FIG. 27. The simulated heat transfer coefficient distribution.

which are $9259.9 \mathrm{~W} /\left(\mathrm{m}^{2} \mathrm{~K}\right)$ for the window channel and $9682.5 \mathrm{~W} /\left(\mathrm{m}^{2} \mathrm{~K}\right)$ for the vane channel. It can be observed in Fig. 27 that the calculated values agree with the average of simulated distribution.

We performed a thermal and structural analysis for the full-length modulated RFQ in both CST and ANSYS. The slight difference between the two results compared in Table VIII can be explained by the different mesh types in the eigenmode solver, as well as in the thermal solver. Figure 28 shows that the maximum temperature and deformation appear at the ends of the two horizontal vanes. This is because the cooling channels cannot reach the vane ends, due to the need to avoid inserting a channel plug along the beam incident direction. Nevertheless, the relatively large deformations $(75 \mu \mathrm{m})$ at the entrance and exit have no serious impact on the beam transmission, as confirmed by beam dynamics simulations.

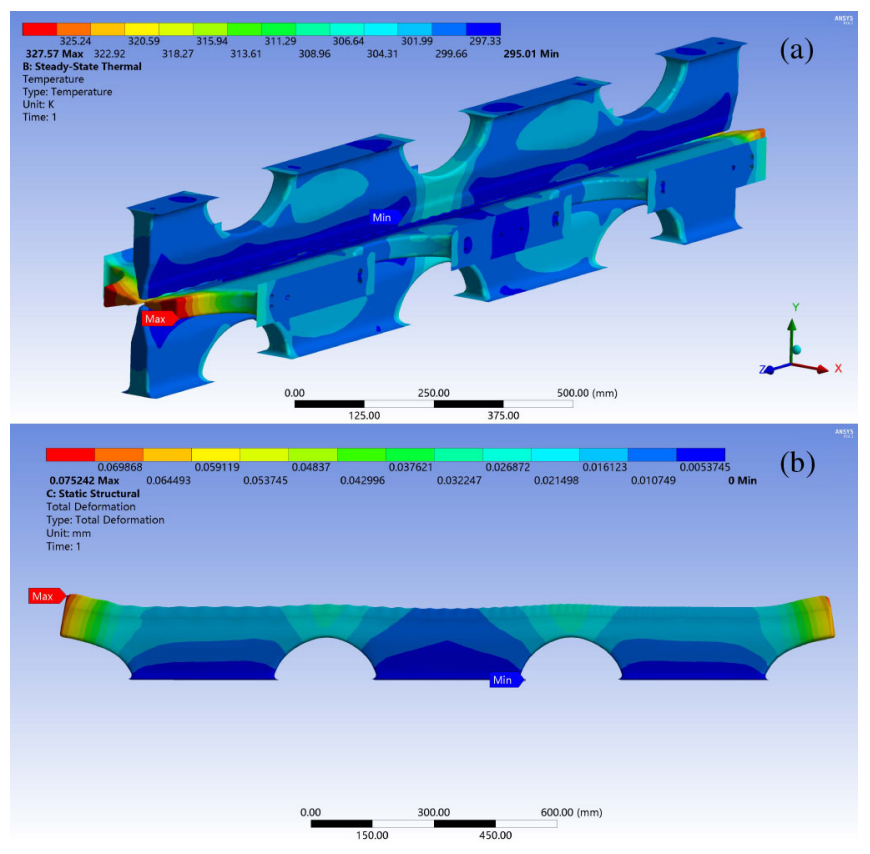

FIG. 28. (a) Temperature map and (b) deformation map of the RFQ vanes.
TABLE VIII. Comparison of the thermal and structural analysis results between CST and ANSYS.

\begin{tabular}{lcc}
\hline \hline Parameter & CST & ANSYS \\
\hline Cooling water velocity $[\mathrm{m} / \mathrm{s}]$ & \multicolumn{2}{c}{2.3} \\
Cooling water temperature $[\mathrm{K}]$ & \multicolumn{2}{c}{291} \\
Background temperature $[\mathrm{K}]$ & \multicolumn{2}{c}{295} \\
Maximal temperature $[\mathrm{K}]$ & 326.20 & 327.57 \\
Maximal absolute deformation $[\mu \mathrm{m}]$ & 73.27 & 75.24 \\
Frequency shift $[\mathrm{MHz}]$ & -0.25 & -0.27 \\
\hline \hline
\end{tabular}

\section{BEAM-LOADING EFFECT AND COUPLER DESIGN}

While passing through the cavity, the beam will not only gain energy from the rf field driven by the generator but will also induce an additional field in the cavity. The superposition of the beam-induced field and the driven field will lead to an amplitude reduction and a phase shift of the cavity field. This effect is referred to as beam loading. Analyzing an equivalent circuit for a beam-loaded cavity, it can be seen from Fig. 29 that the cavity voltage is $\tilde{V}_{c}=\tilde{V}_{g}+\tilde{V}_{b}$, where the beam is treated as a current generator [32].

According to the rf design, our RFQ will consume a total power of $100 \mathrm{~kW}$ in $\mathrm{cw}$ operation, including nearly $50 \mathrm{~kW}$ cavity power $\left(P_{c}\right)$ and $50 \mathrm{~kW}$ beam power $\left(P_{b}\right)$ for accelerating a $50-\mathrm{mA}$ deuteron beam to $1 \mathrm{MeV}$. As the beam-loading ratio $\left(P_{b} / P_{c}\right)$ reaches the value of 1 , the beam-loading effect will become too strong to be ignored as it is for a low-current RFQ and should be compensated.

The compensation method consists of two parts: adjusting the coupling factor for the minimum reflected power and detuning the cavity to compensate for the phase shift. The beam loading changes the input impedance of the cavity; thus, the coupling factor seen looking from the generator to the cavity is reduced to [33]

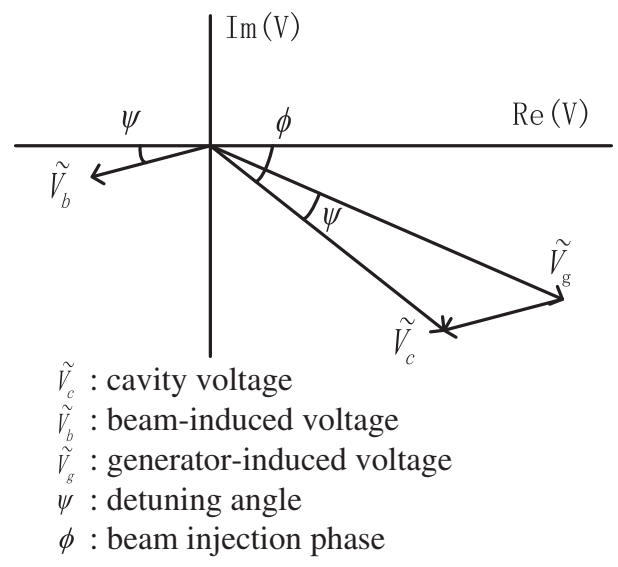

FIG. 29. Voltage phasors for a beam-loaded cavity. 


$$
\beta^{\prime}=\frac{\beta P_{c}}{P_{c}+P_{b}}
$$

where $\beta$ is the waveguide-to-cavity coupler factor. To achieve zero reflected power $\left(\beta^{\prime}=1\right)$ when accelerating a full-current beam to the designed energy, the optimum coupling factor for the beam-loaded cavity should be $\beta_{m}=1+P_{b} / P_{c}=2$. Keeping this coupling factor as a fixed value during RFQ operation would lead to overcoupling and reflected power in the cases of no beam or a beam current lower than $50 \mathrm{~mA}$. Figure 30 plots the change of reflected power with the input beam current. It reaches the maximum value of $6.25 \mathrm{~kW}$ when the current is at zero. To protect the generator and the RFQ cavity, the reflected power should be completely absorbed by the load of a circulator.

Unlike other accelerators, the synchronous phase of an RFQ usually changes from $-90^{\circ}$ to $-30^{\circ}$ during acceleration. To obtain the equivalent synchronous phase $\phi$, we consider all the unit cells of the RFQ as a single accelerating gap. Then the total of $1 \mathrm{MeV}$ energy that the deuteron beams gained can be expressed as

$$
\Delta W=q V_{0} T \cos \phi
$$

where $T=\pi / 4$ is the transit-time factor for an RFQ and $V_{0}$ is the axial $\mathrm{rf}$ voltage, which can be obtained by

$$
V_{0}=\int_{0}^{L} E_{z} d z=\sum_{1}^{n} A_{i} V
$$

In the above equation, $L$ is the RFQ length, $n$ is the total number of unit cells, $A_{i}$ is the acceleration factor of cell $i$, and $V$ is the intervane voltage. For our design, the axial rf voltage is $V_{0}=1.762 \mathrm{MV}$. Thus, the equivalent

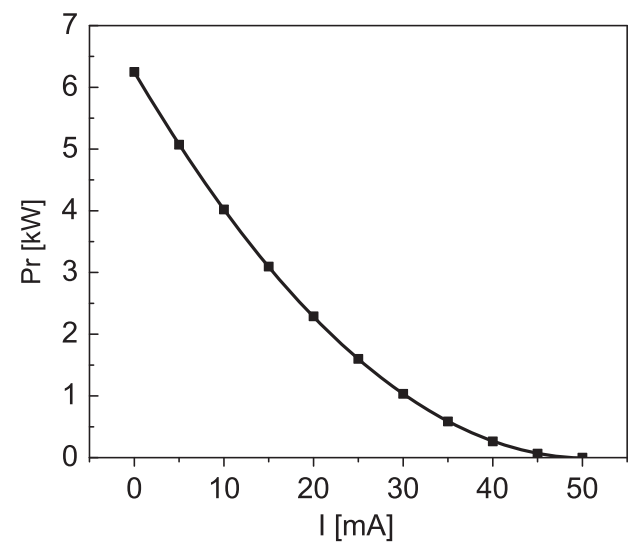

FIG. 30. The reflected power as a function of the input beam current with the optimum coupling factor of 2 . The resonant frequency has been detuned to the optimal value for different values of the beam current. synchronous phase is $\phi=-43.73^{\circ}$. Then the detuning angle $\psi_{m}$ can be calculated to be $17.686^{\circ}$ by [34]

$$
\tan \psi_{m}=-\frac{\beta_{m}-1}{\beta_{m}+1} \tan \phi
$$

The difference between the driven frequency and the cavity resonant frequency can be expressed as

$$
\Delta f / f_{0} \approx \frac{-\tan \psi_{m}}{2 Q_{0} /\left(1+\beta_{m}\right)}
$$

where $Q_{0}$ is the unloaded quality factor. Therefore, in our case, the resonant frequency must be detuned higher than the driven frequency by $8.636 \mathrm{kHz}$.

In the rf power coupler design, to reduce the individual coupler power, two couplers will be integrated with the RFQ. As shown in Fig. 31, the couplers are placed in two opposite quadrants to retain the symmetry of the cavity. In order to generate a strong coupling with the magnetic field without a collision with the tuners, they are located at the longitudinal position of $644.5 \mathrm{~mm}$. The loop area is determined by the coupling factor. Figure 32 shows the simulated change of the coupling factor with the loop area. As the optimum coupling factor for the beam-loaded cavity

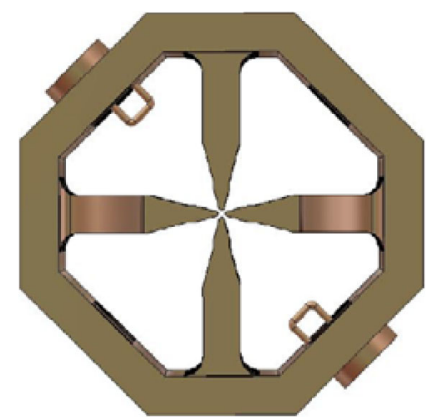

FIG. 31. The two coupler positions relative to the RFQ cavity.

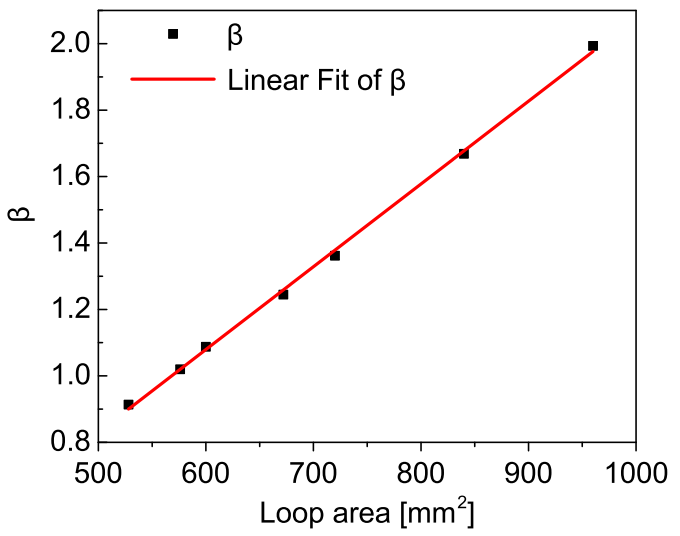

FIG. 32. The relationship between the coupling factor and the loop area. 


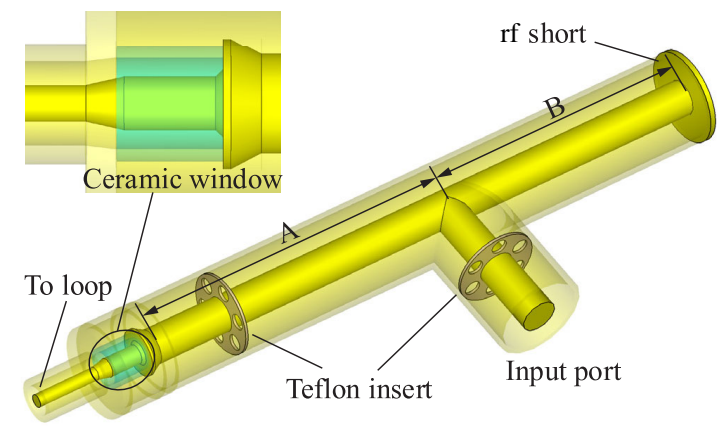

FIG. 33. The rf structure of the coupler with a matching port.

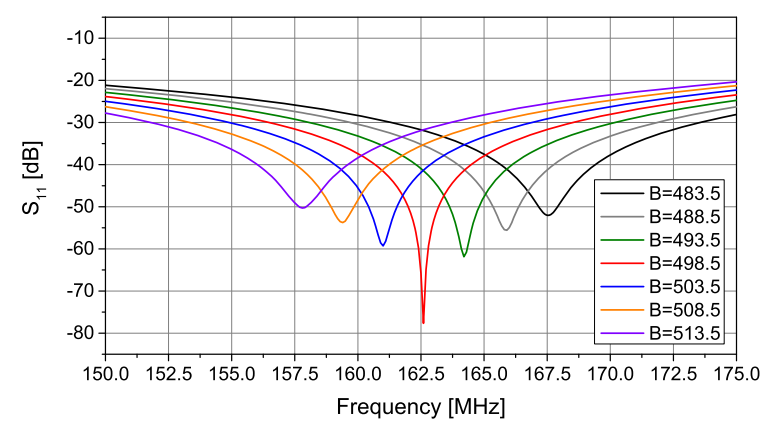

FIG. 34. The change of the simulated $S_{11}$ parameter with length $B$.

is 2 , the coupling factor of each individual coupler is 1 , and the corresponding loop area is approximately $575 \mathrm{~mm}^{2}$.

Figure 33 shows the rf design for the input coupler, with a matching port included, which is a quarter wave of EIA 6 $1 / 8$ " coaxial waveguide. The advantage of this design is that the variable rf short end can not only serve as a cooling water port for heat removal but also suppress the reflected power by varying its length [35]. The length $A$ shown in Fig. 33 is related to the reflection coefficient, and the length $B$ can change the resonant frequency. Figure 34 plots the change of reflection coefficient $\left(S_{11}\right)$ for the input port with the length $B$, with length $A$ fixed at $598.5 \mathrm{~mm}$. The $S_{11}$ parameter is calculated to be lower than $-50 \mathrm{~dB}$ in the range of 158-168 MHz. This indicates that this coupler has a wide passband and does not require high precision during manufacture.

TABLE IX. rf and thermal analysis results of the coupler.

\begin{tabular}{lc}
\hline \hline Parameter & Value \\
\hline Length $A[\mathrm{~mm}]$ & 598.5 \\
Length $B[\mathrm{~mm}]$ & 498.5 \\
Input power $[\mathrm{kW}]$ & 60 \\
Power loss $[\mathrm{W}]$ & 51.6 \\
Maximal volume loss $\left[\mathrm{W} / \mathrm{m}^{3}\right]$ & $5.5 \times 10^{4}$ \\
Maximal surface loss $\left[\mathrm{W} / \mathrm{m}^{2}\right]$ & 1030 \\
Peak electric field $[\mathrm{kV} / \mathrm{m}]$ & 327.3 \\
Maximal temperature rise $[\mathrm{K}]$ & 18.9 \\
\hline \hline
\end{tabular}

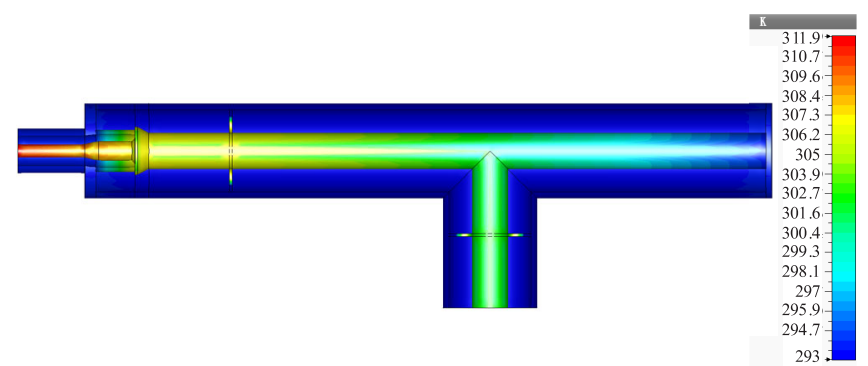

FIG. 35. Temperature distribution of the coupler without including the loop or any cooling.

Table IX lists rf and thermal analysis results for this coupler. With an input power of $60 \mathrm{~kW}$, the total power loss is only $51.6 \mathrm{~W}$, and the peak electric field is far below the breakdown field of $13.6 \mathrm{MV} / \mathrm{m}$. Figure 35 presents the temperature distribution of the coupler without including the loop or any cooling. The maximal temperature rise is $18.9 \mathrm{~K}$, which indicates that this coupler is ideal for operating in the $\mathrm{cw}$ mode.

\section{SUMMARY AND OUTLOOK}

We have carried out a complete design and cold model experiment for a $162.5 \mathrm{MHz}$ deuteron RFQ with a windowtype structure. Many optimizations and new methods were used to increase the chances of success of this 50-mA highcurrent cw RFQ. In the beam dynamics design, optimizing the beam envelope and emittance growth and raising the limiting current above $50 \mathrm{~mA}$ all ensure good beam quality while allowing us to shorten the RFQ length. The low energy spread and the low energy of the beam losses mitigates the risk of deuteron reactions. In the rf structure design, we studied the effect of magnetic coupling windows on the rf performance not only through electromagnetic simulation but also by constructing an equivalent circuit model. The experiment with the cold model confirmed the simulation reliability and provided a good reference for the fabrication of the future copper cavity. During the tuning process, the coupling effect found between quadrants demonstrates the different tuning rule of a window-type RFQ compared to that of a normal fourvane RFQ. Also, we used a conversion from field unflatness to vane potential for a tolerance analysis of the electric field fluctuation. In the cooling system design, we optimized the channels for cooling the coupling windows, significantly improving the cooling efficiency. Finally, we estimated the reflected power due to strong beam loading and designed rf couplers with a wide passband and low power losses.

At present, the mechanical design and process design of the copper cavity are complete and the manufacturing is in progress in a Lanzhou machinery factory. We plan to perform commissioning at the end of 2017. 


\section{ACKNOWLEDGMENTS}

Many thanks to X. Y. Wang and other engineers in Shanghai, who have made great contributions to the cold model fabrication. This work was supported by the National Basic Research Program of China (Grant No. 2014CB845503).

[1] I. M. Kapchinskii and V. A. Teplyakov, A linear ion accelerator with spatially uniform hard focusing, Prib. Tekh. Eksp. 1970, 19 (1969).

[2] Z. S. Hartwig, H. S. Barnard, R. C. Lanza, B. N. Sorbom, P. W. Stahle, and D. G. Whyte, An in situ accelerator-based diagnostic for plasma-material interactions science on magnetic fusion devices, Rev. Sci. Instrum. 84, 123503 (2013).

[3] L. Young, Operations of the LEDA resonantly coupled RFQ, in Proceedings of the 19th Particle Accelerator Conference, Chicago, IL, 2001 (IEEE, Piscataway, NJ, 2001), pp. 309-313.

[4] E. Fagotti, L. Antoniazzi, A. Palmieri, F. Grespan, and M. Desmons, High-power rf conditioning of the TRASCO RFQ, in Proceedings of the 26th International Linear Accelerator Conference, LINAC-2012, Tel Aviv, 2012 (JACoW, Tel Aviv, 2012), pp. 945-947.

[5] B. Pottin, M. Desmons, A. France, R. Gobin, and O. Piquet, Status report on the French high-intensity proton injector project at SACLAY (IPHI), in Proceedings of the 26th International Linear Accelerator Conference, LINAC-2012, Tel Aviv, 2012 (JACoW, Tel Aviv, 2012), pp. 921-923.

[6] P. Fischer, A. Schempp, and J. Hauser, A cw RFQ accelerator for deuterons, in Proceedings of the 21th Particle Accelerator Conference, PAC-2005 Knoxville, TN, 2005 (IEEE, Piscataway, NJ, 2005), pp. 794-795.

[7] J. Knaster, P. Cara, A. Kasughai, Y. Okumura, and M. Sugimoto, Challenges of the high current prototype accelerator of IFMIF/EVEDA, Challenges of the high current prototype accelerator of IFMIF/EVEDA, in Proceedings of the 7th International Particle Accelerator Conference, IPAC-2016, Busan, Korea, 2016 (JACoW, Geneva, 2016), pp. 52-57.

[8] S. S. Kurennoy, L. J. Rybarcyk, and T. P. Wangler, Efficient accelerating structures for low-energy light ions, in Proceedings of the 22nd International Particle Accelerator Conference, PAC-2007, Albuquerque, NM, 2007 (IEEE, New York, 2007), pp. 3824-3826.

[9] V. Andreev and G. Parisi, $90^{\circ}$-apart-stem RFQ structure for wide range of frequencies, in Proceedings of the 15th Particle Accelerator Conference, PAC-1993, Washington, DC, 1993 (IEEE, New York, 1993), pp. 3124-3126.

[10] V. Andreev et al., First beam test of $81.5 \mathrm{MHz}$ RFQ for ITEP-TWAC, in Proceedings of the 2nd International Particle Accelerator Conference, IPAC-2011, San Sebastián, Spain, 2011 (IEEE, San Sebastián, Spain, 2011), pp. 2622-2624.
[11] P. N. Ostroumov et al., Development and beam test of a continuous wave radio frequency quadrupole accelerator, Phys. Rev. ST Accel. Beams 15, 110101 (2012).

[12] A. Perry, C. Dickerson, P. Ostroumov, and G. Zinkann, Beam characterization of a new continuous wave radio frequency quadrupole accelerator, Nucl. Instrum. Methods Phys. Res., Sect. A 735, 163 (2014).

[13] V. Koshelev, Design of 4-vane RFQ with magnetic coupling windows for Nuclotron injector LU-20, in Proceedings of the 28th Linear Accelerator Conference, LINAC-2016, East Lansing, MI, 2016 (JACoW, Geneva, 2016), pp. 575-577.

[14] K. R. Crandall and T.P. Wangler, PARMTEQ-a beam-dynamics code for the RFQ linear accelerator, AIP Conf. Proc. 177, 22 (1988).

[15] T. P. Wangler, Los Alamos Report No. LA-8388, 1980.

[16] F. J. Jia, K. Zhu, Y. R. Lu, Z. Wang, Z. Y. Guo, Q. Fu, and Y. He, Beam Dynamics Design of a $50 \mathrm{~mA} \mathrm{D}+\mathrm{RFQ}$, Chin. Phys. Lett. 33, 072901 (2016).

[17] S. V. Kutsaev, B. Mustapha, P. N. Ostroumov, A. Barcikowski, D. Schrage, J. Rodnizki, and D. Berkovits, Design and multiphysics analysis of a $176 \mathrm{MHz}$ continuous-wave radio-frequency quadrupole, Phys. Rev. ST Accel. Beams 17, 072001 (2014).

[18] CST, http://www.cst.com.

[19] ANSYS, http://www.ansys.com.

[20] J. Delayen, W. Kennedy, and C. Roche, Design and modeling of superconducting RFQ structures, in Proceedings of the 16th Linear Accelerator Conference, LINAC1992, Ottawa, 1992 (JACoW, Ottawa, 1992), pp. 692-695.

[21] D. Uriot and N. Pichoff, TraceWin documentation, CEA/ DSM/DAPNIA/SEA/2000/4, 2000.

[22] B. Mustapha, A. A. Kolomiets, and P. N. Ostroumov, Full three-dimensional approach to the design and simulation of a radio-frequency quadrupole, Phys. Rev. ST Accel. Beams 16, 120101 (2013).

[23] R. Hutcheon, An Equivalent Circuit Model of the General 3-Dimensional RFQ, IEEE Trans. Nucl. Sci. 30, 3524 (1983).

[24] J. Fang and A. Schempp, Equivalent circuit of the 4-rod RFQ, in Proceedings of the 3rd European Particle Accelerator Conference, EPAC-1992, Berlin, 1992 (JACoW, Berlin, 1992), pp. 1331-1333.

[25] U. Ratzinger, H-type linac structures, CERN Accelerator School, 2005.

[26] A. Plastun, Resonance structure with magnetic coupling windows for low and intermediate energy linear ion accelerators, At. Energ. 116, 48 (2014).

[27] R. Hutcheon, A modeling study of the four-rod RFQ, in Proceedings of the 12th International Linear Accelerator Conference, LINAC-1984, Seeheim, Germany, 1984 (JACoW, GSI, 1984), pp. 94-96.

[28] Q. Fu, P. Gan, S. Gao, F. Jia, H. Li, Y. Lu, Z. Wang, K. Zhu, and J. Liu, Study for a $162.5 \mathrm{MHz}$ window-type RFQ, in Proceedings of the 7th International Particle Accelerator Conference, IPAC-2016, Busan, Korea, 2016 (JACoW, Geneva, 2016), pp. 423-425.

[29] R. Duperrier, TOUTATIS: A radio frequency quadrupole code, Phys. Rev. ST Accel. Beams 3, 124201 (2000).

[30] Q. Fu, P. Gan, S. Gao, F. Jia, H. Li, Y. Lu, Z. Wang, and K. Zhu, Progress of a $162.5 \mathrm{MHz}$ high-current RFQ with 
coupling windows, in Proceedings of the 28th Linear Accelerator Conference, LINAC-2016, East Lansing, MI, 2016 (JACoW, Geneva, 2016), pp. 589-591.

[31] F. Kreith, The CRC Handbook of Thermal Engineering (Springer Science, New York, 2000).

[32] P. B. Wilson and J. E. Griffin, High energy electron linacs: applications to storage ring rf systems and linear colliders, AIP Conf. Proc. 87, 450 (1982).

[33] Q. Z. Xing, L. Du, S. X. Zheng, X. L. Guan, J. Li, J. C. Cai, C. K. Gong, X. W. Wang, C. X. Tang, B. James, S. James, and Y. Lloyd, Tuning and cold test of a four-vane RFQ with ramped inter-vane voltage for the compact pulsed hadron source, Chin. Phys. Lett. 30, 052901 (2013).

[34] T. P. Wangler, RF Linear Accelerators (Wiley, New York, 2008).

[35] S. Maebara, A. Palmieri, P. Mereu, M. Ichikawa, H. Takahshi, M. Comunian, H. Suzuki, A. Pisent, and M. Sugimoto, Engineering design of the RF input coupler for the IFMIF prototype RFQ linac, Fusion Eng. Des. 88, 2740 (2013). 